\title{
Identification of key genes and pathways in meningioma by bioinformatics analysis
}

\author{
JUNXI DAI ${ }^{1}$, YANBIN MA ${ }^{1}$, SHENGHUA CHU $^{1}$, NANYANG LE ${ }^{1}$, JUN CAO $^{1}$ and YANG WANG ${ }^{2}$ \\ ${ }^{1}$ Department of Neurosurgery, Shanghai Ninth People's Hospital, Shanghai Jiao Tong University \\ School of Medicine, Shanghai 201900; ${ }^{2}$ Department of Emergency, Xin Hua Hospital Affiliated to \\ Shanghai Jiao Tong University School of Medicine, Shanghai 200082, P.R. China
}

Received April 19, 2017; Accepted November 23, 2017

DOI: $10.3892 / \mathrm{ol} .2018 .8376$

\begin{abstract}
Meningioma is the most frequently occurring type of brain tumor. The present study aimed to conduct a comprehensive bioinformatics analysis of key genes and relevant pathways involved in meningioma, and acquire further insight into the underlying molecular mechanisms. Initially, differentially expressed genes (DEGs) in 47 meningioma samples as compared with 4 normal meninges were identified. Subsequently, these DEGs were subjected to Gene Ontology (GO) and Kyoto Encyclopedia of Genes and Genomes (KEGG) pathway enrichment analyses. In addition, a protein-protein interaction (PPI) network of the identified DEGs was constructed using the Search Tool for the Retrieval of Interacting Genes and visualized using Cytoscape. In total, 1,683 DEGs were identified, including 66 upregulated and 1,617 downregulated genes. The GO analysis results revealed that the DEGs were significantly associated with the 'protein binding', 'cytoplasm', 'extracellular matrix (ECM) organization' and 'cell adhesion' terms. The KEGG analysis results demonstrated the significant pathways included 'AGE-RAGE signaling pathway in diabetic complications', 'PI3K-Akt signaling pathway', 'ECM-receptor interaction' and 'cell adhesion molecules'. The top five hub genes obtained from the PPI network were JUN, PIK3R1, FOS, AGT and MYC, and the most enriched KEGG pathways associated with the four obtained modules were 'chemokine signaling pathway', 'cytokine-cytokine receptor interaction', 'allograft rejection', and 'complement and coagulation cascades'. In conclusion, bioinformatics analysis identified a number of potential biomarkers and relevant pathways that may represent key mechanisms involved in the development and progression of
\end{abstract}

Correspondence to: Dr Yanbin Ma, Department of Neurosurgery, Shanghai Ninth People's Hospital, Shanghai Jiao Tong University School of Medicine, 280 Mohe Road, Baoshan, Shanghai 201900, P.R. China

E-mail:djxcjj@aliyun.com

Key words: meningioma, bioinformatics, protein-protein interaction, signaling pathway, biomarker meningioma. However, these findings require verification in future experimental studies.

\section{Introduction}

Meningiomas are common intracranial tumors that account for $\sim 36 \%$ of all primary central nervous system tumors (1). According to the World Health Organization classification (2), meningiomas may be divided into three grades, including benign (Grade I), atypical (Grade II) and anaplastic (Grade III) meningiomas. Although the majority of meningiomas are benign tumors that are curable by surgery, atypical and anaplastic tumors remain therapeutically challenging due to the high risk of tumor relapse $(3,4)$. Furthermore, even after complete resection, relapse occurs in $>5 \%$ of benign meningiomas $(5,6)$.

The pathogenesis of meningioma is a complex process associated with an accumulation of various genetic and epigenetic alterations that occur during the initiation and progression of the tumor (7). Monosomy 22, 22q deletion and/or mutation of the neurofibromatosis type 2 gene have been identified as important initiating events and represent the most common genetic alterations in meningiomas (8-10). Other common chromosomal alterations include deletions of $1 \mathrm{p}, 6 \mathrm{q}, 10 \mathrm{q}$ and $14 \mathrm{q}$, and insertions of 1q, 9q, 12q, 15q, 17q and 20q $(7,11,12)$. However, there is insufficient evidence to verify the capability of these chromosomal alterations to predict tumor recurrence and progression.

Several gene expression profiling studies have been conducted on meningiomas, and several candidate genes have been proposed as recurrence-associated predictors or progression-associated biomarkers of meningiomas among the differentially expressed genes (DEGs), including KLF4, GAB2, TRAF7,LMO3, SMO and TSLC1 (13-16). Additionally, the prognostic capabilities of CKS2, PTTG1 and the leptin receptor have also been indicated by mixed transcriptome analyses $(17,18)$. However, research has mainly focused on identifying candidate genes that may be potential novel biomarkers for meningioma, while the possible intrinsic links among DEGs have not been extensively investigated. Studies aimed at identifying the key pathways and characteristics of the biology involved in this tumor remain limited $(11,14,17,18)$.

Traditional biology research can reveal molecular mechanisms based on the variation and function of an individual 
gene, mRNA or protein; however, it only describes the biological phenomenon of a disease from a partial viewpoint, rather than describing it in the context of the entire system. Bioinformatics analysis is a powerful tool that provides a novel platform to study the characteristics of biology at a more holistic perspective and elaborate the association of different functional elements $(7,15,18)$.

In the present study, bioinformatics analysis was conducted to determine several potential biomarkers of meningioma (namely JUN, PIK3R1, FOS, AGT and MYC), as well as to identify relevant pathways (including the AGE-RAGE signaling pathway in diabetic complications, PI3K-Akt signaling pathway, ECM-receptor interaction and cell adhesion among others), which are potentially involved in the onset and progression of meningioma. Furthermore, clinical evidence exists to verify the capability of these aforementioned biomarkers and pathways in the prediction of meningioma recurrence and progression. In conclusion, the findings of the present study provide further insight into the pathogenesis of meningiomas and provide potential therapeutic targets for further studies.

\section{Materials and methods}

Source of data. Initially, the microarray expression profile of the GSE43290 data set was downloaded from the Gene Expression Omnibus (GEO) database (19). The GSE43290 data set, which includes 47 meningioma samples and 4 normal meningeal samples, was submitted by Tabernero et al (20). The platform of these microarray data, GPL96 [HG-U133A] Affymetrix Human Genome U133A Array, was also downloaded from the GEO database. Using the affy package in $\mathrm{R}$ software (version 3.25; www.r-project.org) (21), the obtained raw data were preprocessed, which involved background correction, quartile normalization and probe summarization.

Extraction of differentially expressed genes (DEGS). A Student's t-test in the Limma package in R software (22) was performed to identify the DEGs between the meningioma and normal meningeal (control) samples. All genes that met the following criteria were selected as DEGs: P-value of $<0.05$ and $\mid \log _{2}$ (fold change)| of $>1$. A heat map of the extracted DEGs was then created through the gplots package in $\mathrm{R}$, in order to visualize the expression values of genes in the different samples.

Functional enrichment analysis of DEGs. Following extraction of the DEGs, Gene Ontology (GO) and Kyoto Encyclopedia Genes and Genomes (KEGG) pathway enrichment analyses were conducted. GO analysis is a common bioinformatics method for identifying characteristic biological attributes in large-scale genomic and transcriptomic data (23). KEGG is a database for the systematic analysis of genetic functions that links genomic information with higher order functional information (24). In the present study, the GO analysis was conducted via the Database for Annotation, Visualization and Integrated Discovery (DAVID; https://david.ncifcrf.gov), a web-based tool for systematic functional analysis (25). The GO categories selected included 'biological process', 'molecular function' and 'cellular component'. The KEGG pathway analysis of the DEGs was conducted through the
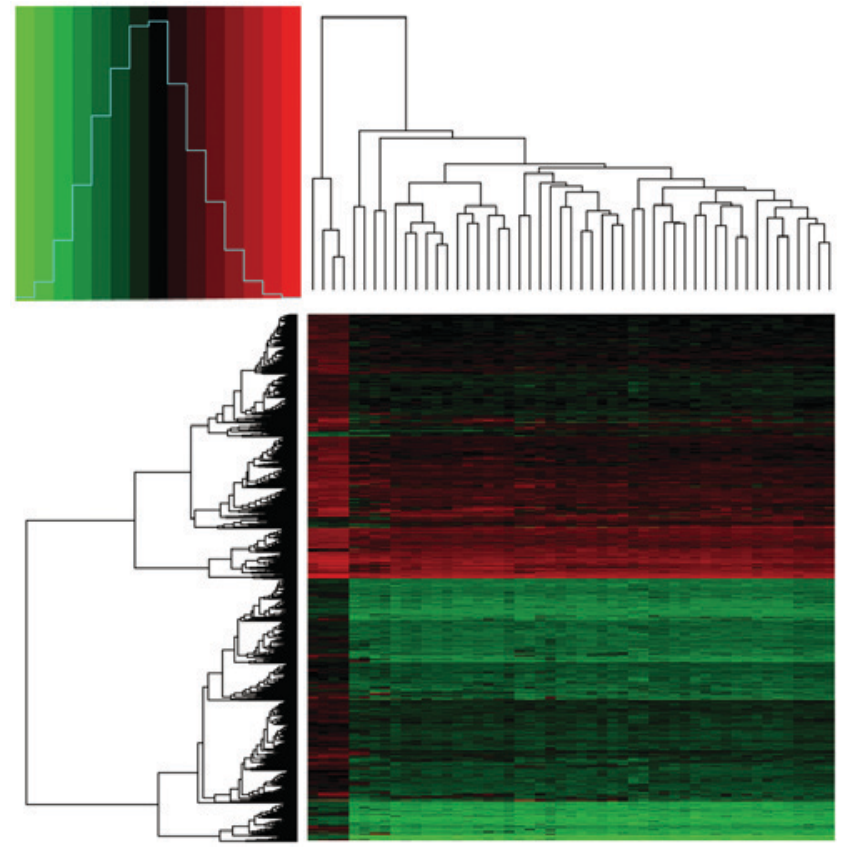

Figure 1. Heat map of differentially expressed genes associated with meningioma. The data are presented in a matrix format, in which rows represent individual genes and columns represent each sample. The red and green colors indicate upregulated and downregulated genes, respectively.

ClusterProfiler package in R software. A P-value of $<0.05$ was selected as the cut-off criterion.

Integration of protein-protein interaction (PPI) network and module analysis. PPI network analysis is a method for identifying the associations among various proteins. To acquire further insights into the molecular mechanisms of meningioma, the list of DEGs was entered into the Search Tool for the Retrieval of Interacting Genes (STRING) database, which is an online database designed to evaluate PPI information (26). Using this tool, gene-gene interactions with a combined score of $>0.9$ were selected to construct the PPI network. Cytoscape software (version 3.4.0) was then used to visualize the obtained PPI network (27).

All genes with a connectivity degree (defined as the number of other genes that directly interact with that particular gene) of $>20$ were selected as hub genes in the network. The core genes were the most likely to be involved in meningioma and to be potential biomarkers of tumor development and progression. In addition, significant modules of the PPI network were identified using the Molecular Complex Detection (MCODE) Cytoscape plug-in. An MCODE score (indicating the density of nodes) of $>10$ and node number of $>10$ were selected as the significance threshold criteria. Next, KEGG pathway enrichment analysis of the DEGs in these modules was performed using DAVID aiming to evaluate the genetic functions at the molecular level. A P-value of $\mathrm{P}<0.05$ was selected as the cut-off criterion for identifying the significant pathways associated with these modules.

\section{Results}

DEGs in meningioma vs.normal meningeal tissues. According to the t-test analysis of the DEGs in the 47 tumor samples 
Table I. GO analysis of differentially expressed genes associated with meningioma.

\begin{tabular}{|c|c|c|c|}
\hline Category & Term & Count & P-value \\
\hline GOTERM_MF_DIRECT & Protein binding & 931 & $5.26 \times 10^{-15}$ \\
\hline GOTERM_CC_DIRECT & Cytoplasm & 587 & $1.36 \times 10^{-13}$ \\
\hline GOTERM_BP_DIRECT & Extracellular matrix organization & 53 & $1.22 \times 10^{-12}$ \\
\hline GOTERM_CC_DIRECT & Cytosol & 397 & $2.33 \times 10^{-12}$ \\
\hline GOTERM_BP_DIRECT & Cell adhesion & 91 & $2.85 \times 10^{-12}$ \\
\hline GOTERM_CC_DIRECT & Extracellular exosome & 344 & $8.41 \times 10^{-12}$ \\
\hline GOTERM_CC_DIRECT & Extracellular matrix & 61 & $5.24 \times 10^{-10}$ \\
\hline GOTERM_CC_DIRECT & Focal adhesion & 73 & $9.24 \times 10^{-10}$ \\
\hline GOTERM_CC_DIRECT & $\mathrm{Z}$ disc & 34 & $1.06 \times 10^{-9}$ \\
\hline GOTERM_BP_DIRECT & Angiogenesis & 51 & $2.10 \times 10^{-9}$ \\
\hline GOTERM_CC_DIRECT & Extracellular space & 181 & $2.87 \times 10^{-9}$ \\
\hline GOTERM_BP_DIRECT & Signal transduction & 166 & $5.42 \times 10^{-9}$ \\
\hline GOTERM_BP_DIRECT & Positive regulation of transcription from RNA polymerase II promoter & 140 & $1.15 \times 10^{-7}$ \\
\hline GOTERM_CC_DIRECT & Extracellular region & 201 & $1.16 \times 10^{-7}$ \\
\hline GOTERM_MF_DIRECT & Transcription factor binding & 54 & $2.02 \times 10^{-7}$ \\
\hline GOTERM_CC_DIRECT & Stress fiber & 19 & $3.71 \times 10^{-7}$ \\
\hline GOTERM_BP_DIRECT & Positive regulation of angiogenesis & 30 & $3.72 \times 10^{-7}$ \\
\hline GOTERM_MF_DIRECT & Identical protein binding & 109 & $3.97 \times 10^{-7}$ \\
\hline GOTERM_CC_DIRECT & Integral component of plasma membrane & 178 & $4.34 \times 10^{-7}$ \\
\hline GOTERM_CC_DIRECT & Cell surface & 83 & $6.11 \times 10^{-7}$ \\
\hline GOTERM_BP_DIRECT & Type I interferon signaling pathway & 21 & $6.20 \times 10^{-7}$ \\
\hline GOTERM_BP_DIRECT & Negative regulation of cell proliferation & 68 & $6.72 \times 10^{-7}$ \\
\hline GOTERM_BP_DIRECT & Immune response & 71 & $7.37 \times 10^{-7}$ \\
\hline GOTERM_BP_DIRECT & Response to hypoxia & 38 & $7.54 \times 10^{-7}$ \\
\hline GOTERM_CC_DIRECT & Myelin sheath & 34 & $7.94 \times 10^{-7}$ \\
\hline GOTERM_CC_DIRECT & Membrane raft & 41 & $1.24 \times 10^{-6}$ \\
\hline GOTERM_CC_DIRECT & Neuron projection & 45 & $1.34 \times 10^{-6}$ \\
\hline GOTERM_CC_DIRECT & Actin filament & 20 & $1.73 \times 10^{-6}$ \\
\hline GOTERM_BP_DIRECT & Positive regulation of apoptotic process & 54 & $2.63 \times 10^{-6}$ \\
\hline GOTERM_CC_DIRECT & Proteinaceous extracellular matrix & 48 & $3.10 \times 10^{-6}$ \\
\hline
\end{tabular}

$\mathrm{GO}$, Gene ontology; MF, molecular function; CC, cellular component; BP, biological process.

compared with the 4 normal meningeal samples, a total of 1,683 DEGs were identified, including 66 upregulated and 1,617 downregulated genes. The heat map of DEG expression is shown in Fig. 1.

Enriched GO terms and KEGG pathways of the identified DEGs. In the present study, a total of 649 enriched GO terms and 34 KEGG pathways were identified. The top 30 enriched GO terms of the DEGs according to the P-value threshold $(\mathrm{P}<0.05)$ are shown in Table I. The downregulated genes were significantly associated with 'protein binding', 'cytoplasm', 'extracellular matrix (ECM) organization' and 'cell adhesion', whereas there were no GO terms that were significantly enriched among the upregulated DEGs. The enriched KEGG pathways of the DEGs are shown in Table II. A number of the enriched KEGG pathways were directly associated with cancer, including the 'pathways in cancer' and 'small cell lung cancer' pathways. Furthermore, there was enrichment of certain other pathways that are potentially involved in the development and progression of meningiomas via various biological processes, including the 'AGE-RAGE signaling pathway in diabetic complications', 'PI3K-Akt signaling pathway', 'ECM-receptor interaction' and 'cell adhesion molecules'.

Module screening from the PPI network. Based on the STRING data, a PPI network of 807 nodes and 2,598 edges was obtained. Nodes with a connectivity degree of $>20$ were determined as hub genes (Table III). Among them, the top five genes according to their connectivity degree were JUN, PIKR1, FOS, AGT and MYC. In addition, according to the connectivity degree of nodes in modules. The top 4 modules with MCODE score of $>10$ and node number of $>10$ were obtained (Fig. 2). Functional annotation results revealed that the genes in modules 1,2 and 4 were mainly associated with the 'chemokine signaling pathway', 'cytokine-cytokine receptor interaction', 'allograft rejection', and 'complement and coagulation cascades', while there were no enriched pathways associated with the DEGs in module 3 (Table IV). 
Table II. Enriched Kyoto Encyclopedia of Genes and Genomes pathways of differentially expressed genes associated with meningioma.

\begin{tabular}{|c|c|c|c|}
\hline Pathway ID & Description & Gene count & P-value \\
\hline hsa04933 & AGE-RAGE signaling pathway in diabetic complications & 32 & $7.86 \times 10^{-9}$ \\
\hline hsa04151 & PI3K-Akt signaling pathway & 70 & $3.98 \times 10^{-8}$ \\
\hline hsa04668 & TNF signaling pathway & 32 & $7.73 \times 10^{-8}$ \\
\hline hsa04512 & ECM-receptor interaction & 26 & $1.98 \times 10^{-7}$ \\
\hline hsa04510 & Focal adhesion & 46 & $3.84 \times 10^{-7}$ \\
\hline hsa05410 & Hypertrophic cardiomyopathy & 23 & $1.28 \times 10^{-5}$ \\
\hline hsa04066 & HIF-1 signaling pathway & 26 & $2.21 \times 10^{-5}$ \\
\hline hsa04210 & Apoptosis & 32 & $2.36 \times 10^{-5}$ \\
\hline hsa05146 & Amoebiasis & 25 & $2.62 \times 10^{-5}$ \\
\hline hsa05414 & Dilated cardiomyopathy & 23 & $5.30 \times 10^{-5}$ \\
\hline hsa05200 & Pathways in cancer & 67 & $9.01 \times 10^{-5}$ \\
\hline hsa05144 & Malaria & 15 & $1.21 \times 10^{-4}$ \\
\hline hsa05222 & Small cell lung cancer & 21 & $2.22 \times 10^{-4}$ \\
\hline hsa05134 & Legionellosis & 15 & $4.93 \times 10^{-4}$ \\
\hline hsa05031 & Amphetamine addiction & 17 & $6.46 \times 10^{-4}$ \\
\hline hsa04657 & IL-17 signaling pathway & 21 & $6.90 \times 10^{-4}$ \\
\hline hsa05161 & Hepatitis B & 29 & $7.24 \times 10^{-4}$ \\
\hline hsa04978 & Mineral absorption & 14 & $8.68 \times 10^{-4}$ \\
\hline hsa04068 & FoxO signaling pathway & 27 & $8.68 \times 10^{-4}$ \\
\hline hsa04010 & MAPK signaling pathway & 44 & $9.13 \times 10^{-4}$ \\
\hline hsa04064 & $\mathrm{NF}-\kappa \mathrm{B}$ signaling pathway & 21 & $9.27 \times 10^{-4}$ \\
\hline hsa04060 & Cytokine-cytokine receptor interaction & 46 & $9.30 \times 10^{-4}$ \\
\hline hsa05416 & Viral myocarditis & 15 & $1.10 \times 10^{-3}$ \\
\hline hsa05412 & Arrhythmogenic right ventricular cardiomyopathy & 17 & $1.29 \times 10^{-3}$ \\
\hline hsa05202 & Transcriptional misregulation in cancer & 33 & $1.39 \times 10^{-3}$ \\
\hline hsa04514 & Cell adhesion molecules & 28 & $1.40 \times 10^{-3}$ \\
\hline hsa05166 & HTLV-I infection & 43 & $2.10 \times 10^{-3}$ \\
\hline hsa04261 & Adrenergic signaling in cardiomyocytes & 28 & $2.14 \times 10^{-3}$ \\
\hline hsa04022 & cGMP-PKG signaling pathway & 30 & $3.39 \times 10^{-3}$ \\
\hline hsa04145 & Phagosome & 28 & $3.51 \times 10^{-3}$ \\
\hline hsa04610 & Complement and coagulation cascades & 17 & $3.71 \times 10^{-3}$ \\
\hline hsa04621 & NOD-like receptor signaling pathway & 30 & $4.06 \times 10^{-3}$ \\
\hline hsa05162 & Measles & 25 & $4.86 \times 10^{-3}$ \\
\hline hsa04921 & Oxytocin signaling pathway & 28 & $5.09 \times 10^{-3}$ \\
\hline
\end{tabular}

\section{Discussion}

Although previous studies have proposed numerous potential biomarkers associated with the progression and recurrence of meningiomas, the knowledge regarding the molecular mechanisms of meningioma remains relatively limited (13,16-18). In the present study, a comprehensive analysis of the gene expression profiles of meningiomas and normal meninges was conducted using a combined bioinformatics approach. A total of 1,683 DEGs (66 upregulated and 1,617 downregulated) were identified. Functional enrichment analysis revealed that these DEGs were mainly involved in ECM organization, cell adhesion, angiogenesis and signal transduction. By constructing a PPI network, a number of hub genes were identified as potential prognostic biomarkers for meningioma.
The gene expression data of 47 meningioma samples and 4 normal controls included in the present study were downloaded from the GEO database with the accession number GSE43290. The 47 tumor samples were composed of 18 diploid tumors, 12 tumors with monosomy 22/del (22q) alone, 4 tumors with del (1p36) alone, and 13 with complex karyotypes associated with del (1p36) and/or del (14q), which are the most frequently altered cytogenetic subgroups of meningiomas in clinical practice $(5,12)$.

The approach used in the current study identified 1,683 DEGs, including 1,617 downregulated and 66 upregulated genes, in meningioma samples as compared with those in normal meninges. These results indicated that gene expression in meningiomas was generally downregulated, which may be attributed to the loss of chromosomal material in meningioma. 
Table III. Hub genes and their corresponding degree.

\begin{tabular}{|c|c|}
\hline Gene symbol & Degree \\
\hline JUN & 79 \\
\hline PIK3R1 & 56 \\
\hline FOS & 53 \\
\hline AGT & 53 \\
\hline MYC & 50 \\
\hline STAT3 & 47 \\
\hline LPAR1 & 47 \\
\hline IL8 & 44 \\
\hline HSP90AA1 & 41 \\
\hline CXCL12 & 41 \\
\hline NFKB1 & 41 \\
\hline RPS27A & 40 \\
\hline GNAI1 & 39 \\
\hline РPBP & 37 \\
\hline CXCR4 & 35 \\
\hline HIF1A & 33 \\
\hline NPY & 32 \\
\hline S1PR1 & 32 \\
\hline CCL5 & 31 \\
\hline SST & 30 \\
\hline IL6 & 30 \\
\hline EDN1 & 30 \\
\hline EGR1 & 28 \\
\hline STAT1 & 28 \\
\hline IRF1 & 28 \\
\hline CCR7 & 28 \\
\hline CXCL2 & 28 \\
\hline SSTR2 & 27 \\
\hline CCL19 & 27 \\
\hline RGS1 & 27 \\
\hline RGS4 & 27 \\
\hline CXCL9 & 27 \\
\hline CXCL1 & 27 \\
\hline ADRA2A & 27 \\
\hline HTR1B & 27 \\
\hline HTR1D & 27 \\
\hline CXCL3 & 27 \\
\hline C5AR1 & 27 \\
\hline MTNR1B & 27 \\
\hline APLNR & 27 \\
\hline P2RY14 & 27 \\
\hline HCAR3 & 27 \\
\hline ICAM1 & 25 \\
\hline CDKN1A & 24 \\
\hline CCND1 & 23 \\
\hline PTEN & 23 \\
\hline NOS3 & 23 \\
\hline ACTN1 & 23 \\
\hline IRF7 & 23 \\
\hline KALRN & 23 \\
\hline IRF9 & 22 \\
\hline HLA-A & 22 \\
\hline
\end{tabular}

Table III. Continued.

\begin{tabular}{lc}
\hline Gene symbol & Degree \\
\hline YWHAE & 22 \\
SIRT1 & 21 \\
CDH1 & 21 \\
GNAQ & 21 \\
ISG15 & 20 \\
\hline
\end{tabular}

In addition, $\mathrm{GO}$ analysis revealed that the enriched ontological categories among the DEGs mainly included ECM organization, cell adhesion, angiogenesis, signal transduction and negative regulation of cell proliferation. Previous studies have revealed that matrix metalloproteinases (MMPs), which are mediators of invasion and angiogenesis, may serve important roles in the invasion and recurrence of meningioma $(28,29)$. Indeed, cumulative evidence has demonstrated that the contribution of MMPs to tumor progression may be associated with the regulation of cell adhesion, the control of apoptosis via the release of factors associated with cell death or survival, and the proteolysis of the ECM $(28,30,31)$. Previous studies have demonstrated that the aforementioned GO terms are potentially important events in meningioma development and tumor progression. Furthermore, the KEGG pathway analysis results in the present study revealed that 'ECM-receptor interaction', 'apoptosis' and 'cell adhesion molecules' were among the significantly enriched pathways associated with the DEGs. These findings were consistent with those of a study by Keller et al (32), which also suggested that 'ECM-receptor interaction' and 'cell adhesion molecules' were significantly dysregulated pathways in meningioma. Therefore, monitoring these biological processes and pathways may aid in the prediction of meningioma development and progression. Furthermore, 31 other enriched pathways were identified in the current study, including 'AGE-RAGE signaling pathway in diabetic complications', 'PI3K-Akt signaling pathway', 'TNF signaling pathway' and 'focal adhesion'. The PI3K-Akt signaling pathway is an intracellular signaling pathway that is important in regulating the cell cycle progression, cell death and cell growth (33). Alterations in this pathway are frequently identified as being involved in the development of various types of cancer $(34,35)$.

The top five hub genes identified from a PPI network constructed from the DEGs in the present study were JUN, PIK3R1, FOS, AGT and MYC. Among these hub genes, JUN, a protein-coding gene, exhibited the highest degree of connectivity. JUN is an important component of activator protein 1 (AP-1), a transcription factor that recognizes the specific DNA sequence TGAC/GTCA. This gene modulates numerous biological functions involved in the regulation of cell proliferation, apoptosis and transformation (36). The aberrant expression of JUN has been reported in various types of cancer, including glioblastoma and hepatocellular carcinoma $(37,38)$. Furthermore, FOS is a member of the Fos family that encodes leucine zipper proteins that form heterodimers with the JUN family, resulting in the formation of AP-1 (39). Thus, this gene also serves important roles in cell proliferation, differentiation and transformation (40). Significant associations between 
Table IV. Enriched Kyoto Encyclopedia of Genes and Genomes pathways of four modules.

\begin{tabular}{|c|c|c|}
\hline Pathway term & P-value & Nodes \\
\hline \multicolumn{3}{|l|}{ Module 1} \\
\hline Chemokine signaling pathway & $1.14 \times 10^{-10}$ & $\begin{array}{l}\text { CXCL1, CCR7, PPBP, IL8, GNAI1, CXCR4, CXCL3, CXCL2, } \\
\text { CXCL9, CCL19, CCL5, CXCL12 }\end{array}$ \\
\hline Cytokine-cytokine receptor interaction & $7.02 \times 10^{-8}$ & $\begin{array}{l}\text { CXCL1, CCR7, PPBP, IL8, CXCR4, CXCL3, CXCL2, CXCL9, } \\
\text { CCL19, CCL5, CXCL12 }\end{array}$ \\
\hline Neuroactive ligand-receptor interaction & $7.93 \times 10^{-7}$ & $\begin{array}{l}\text { APLNR, HTR1B, SSTR2, C5AR1, S1PR1, P2RY14, } \\
\text { ADRA2A, MTNR1B, LPAR1, HTR1D }\end{array}$ \\
\hline \multicolumn{3}{|l|}{ Module 2} \\
\hline Allograft rejection & 0.0418 & HLA-A, HLA-C \\
\hline Graft-versus-host disease & 0.0452 & HLA-A, HLA-C \\
\hline Type I diabetes mellitus & 0.0486 & HLA-A, HLA-C \\
\hline \multicolumn{3}{|l|}{ Module 3} \\
\hline No record & - & - \\
\hline \multicolumn{3}{|l|}{ Module 4} \\
\hline Complement and coagulation cascades & 0.0012 & VWF, A2M, F13A1, SERPINE1 \\
\hline Calcium signaling pathway & 0.0018 & AGTR1, EDNRB, GNAQ, PTGFR, HTR2A \\
\hline Renal cell carcinoma & 0.0198 & VEGFC, TGFB3, PIK3R1 \\
\hline
\end{tabular}
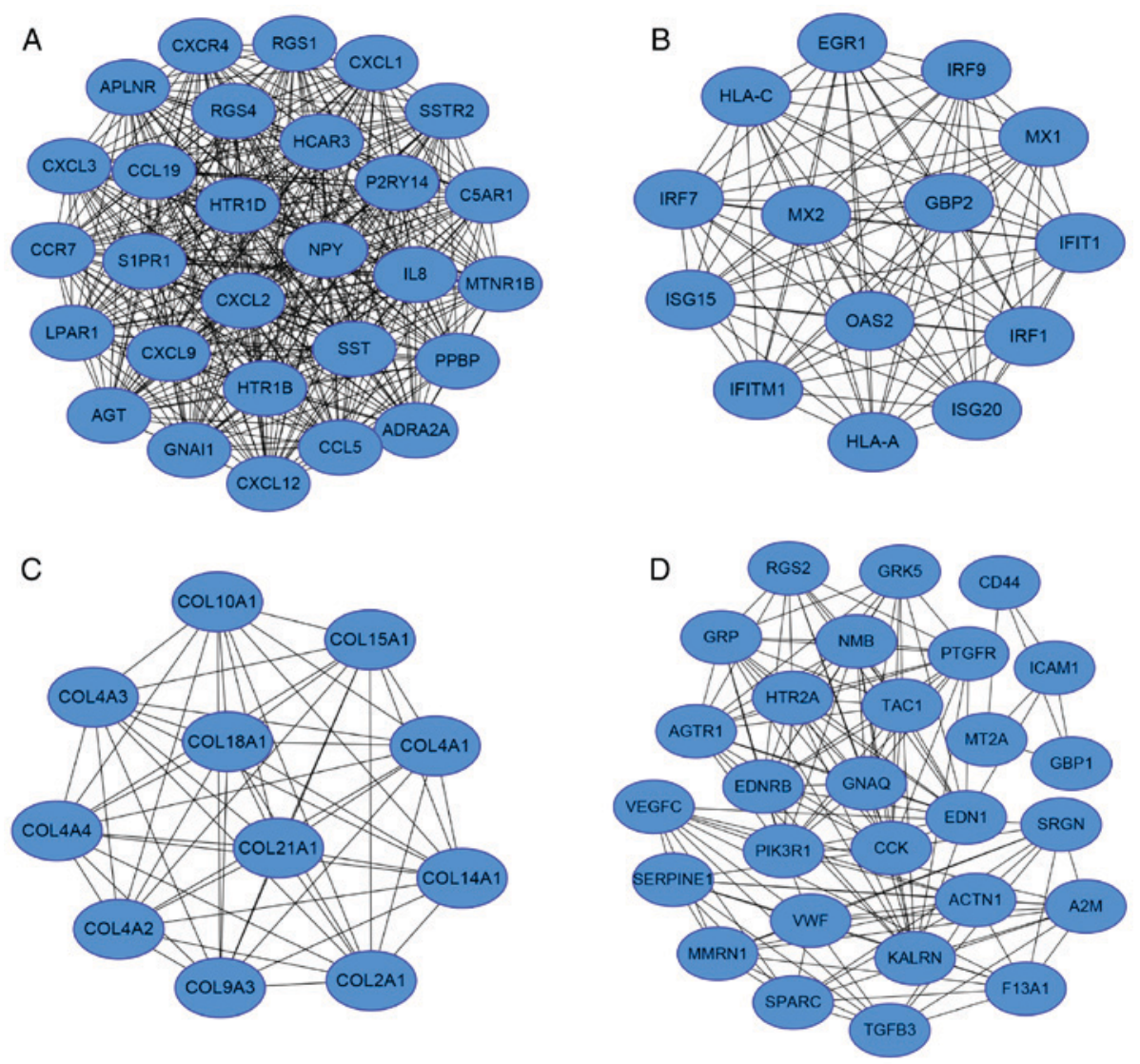

Figure 2. Top 4 modules with the higher connectivity degrees identified in the protein-protein interaction network analysis. (A) Module 1, (B) module 2, (C) module 3 and (D) module 4 are shown.

FOS and various tumors have also been identified in previous studies $(41,42)$.

PIK3R1, another hub gene identified in the present study, is a critical mediator of insulin sensitivity, and mutation of this gene is associated with insulin resistance, which is an important mechanism involved in human obesity $(43,44)$. McCurdy et al $(45)$ reported that, in diet-induced obese mice, attenuated PIK3R1 expression was able to prevent insulin resistance. Recently, 
a large case-control study further suggested that obesity was positively associated with a risk of meningioma (46).

The AGT gene, also identified in the current study, is a member of the renin-angiotensin system-associated gene family, which is physiologically important for blood pressure regulation and may be involved in the pathogenesis of hypertension (47). Accumulating evidence has demonstrated that increased blood pressure is an independent and additive risk factor for the development of brain tumors, particularly meningiomas (46).

Another hub gene, MYC, is located on chromosome 8 and has been closely correlated with cell growth, apoptosis and cellular transformation (48). Mutation, overexpression, rearrangement and translocation of this gene have been detected in a variety of tumors, including Burkitt's lymphoma, medulloblastoma and hepatocellular carcinoma among others (49-51).

In the present study, module analysis of the PPI network revealed that the development of meningioma was possibly associated with the chemokine signaling pathway, cytokine-cytokine receptor interaction, allograft rejection, and complement and coagulation cascades. This is consistent with the observations of the study by Keller et al (32), which analyzed the expression profiles of 24 meningiomas and identified 'cytokine-cytokine receptor interaction' and 'complement pathway and coagulation cascades' as two of the main pathways enriched among the downregulated genes.

In conclusion, by applying a comprehensive bioinformatics analysis of DEGs, the present study identified several hub genes, including JUN, PIK3R1, FOS, AGT and MYC, that may be functionally relevant to the pathogenesis of meningioma. The functional analysis results also revealed a number of potentially significant pathways that may participate in meningioma development and progression, including 'AGE-RAGE signaling pathway in diabetic complications', 'PI3K-Akt signaling pathway', 'ECM-receptor interaction' and 'cell adhesion molecules'. These results provided further insight into the underlying molecular mechanisms of meningioma. Further experimental studies are required to confirm these observations and to determine their potential as molecular targets in the development of novel therapeutic approaches for meningioma.

\section{Acknowledgements}

Not applicable.

\section{Funding}

The present study was supported by a grant from the Shanghai Jiao Tong University Medicine and Engineering Cross Fund (grant no. YG 2015MS25).

\section{Availability of data and materials}

The datasets analyzed during the current study (GSE43290) were downloaded from a public dataset webset from the Gene Expression Omnibus (https://www.ncbi.nlm.nih.gov/geo/ query/acc.cgi?acc=GSE43290).

\section{Authors' contributions}

JD analyzed and interpreted the microarray data regarding meningomas. YM and SC renalyzed the data and confirmed the results' authenticity. NL and JC designed this bioinformatic study and wrote the manuscript. YW was responsible for making tables, drawing the fgures, and helped JD to interprete the findings from the study. All authors read and approved the final manuscript.

\section{Ethics approval and consent to participate}

Not applicable.

\section{Consent for publication}

Not applicable.

\section{Competing interests}

The authors declare that they have no competing interests.

\section{References}

1. Ostrom QT, Blank PMD, Kruchko C, Petersen CM, Liao P, Finlay JL, Stearns DS, Wolff JE, Wolinsky Y, Letterio JJ and Barnholtz-Sloan JS: Alex's lemonade stand foundation infant and childhood primary brain and central nervous system tumors diagnosed in the united states in 2007-2011. Neuro Oncol 16 (Suppl 10): x1-x36, 2015.

2. Louis DN, Ohgaki H, Wiestler OD, Cavenee WK, Burger PC, Jouvet A, Scheithauer BW and Kleihues P: The 2007 WHO classification of tumours of the central nervous system. Acta Neuropathol 114: 97-109, 2007.

3. Yang SY, Park CK, Park SH, Kim DG, Chung YS and Jung HW: Atypical and anaplastic meningiomas: Prognostic implications of clinicopathological features. J Neurol Neurosurg Psychiatry 79: 574-580, 2008.

4. Riemenschneider MJ, Perry A and Reifenberger G: Histological classification and molecular genetics of meningiomas. Lancet Neurol 5: 1045-1054, 2006.

5. Maillo A, Orfao A, Espinosa AB, Sayagués JM, Merino M, Sousa P, Lara M and Tabernero MD: Early recurrences in histologically benign/grade I meningiomas are associated with large tumors and coexistence of monosomy 14 and del(1p36) in the ancestral tumor cell clone. Neuro Oncol 9: 438-446, 2007.

6. Perry A, Scheithauer BW, Stafford SL, Lohse CM and Wollan PC: 'Malignancy' in meningiomas: A clinicopathologic study of 116 patients, with grading implications. Cancer 85: 2046-2056, 1999.

7. Mawrin C and Perry A: Pathological classification and molecular genetics of meningiomas. J Neurooncol 99: 379-391, 2010.

8. Lomas J, Bello MJ, Arjona D, Alonso ME, Martinez-Glez V, Lopez-Marin I, Amiñoso C, de Campos JM, Isla A, Vaquero J and Rey JA: Genetic and epigenetic alteration of the NF2 gene in sporadic meningiomas. Genes Chromosomes Cancer 42: 314-319, 2005.

9. Harada T, Irving RM, Xuereb JH, Barton DE, Hardy DG, Moffat DA and Maher ER: Molecular genetic investigation of the neurofibromatosis type 2 tumor suppressor gene in sporadic meningioma. J Neurosurg 84: 847-851, 1996.

10. Ng HK, Lau KM, Tse JY, Lo KW, Wong JH, Poon WS and Huang DP: Combined molecular genetic studies of chromosome $22 \mathrm{q}$ and the neurofibromatosis type 2 gene in central nervous system tumors. Neurosurgery 37: 764-773, 1995.

11. Choy W, Kim W, Nagasawa D, Stramotas S, Yew A, Gopen Q, Parsa AT and Yang I: The molecular genetics and tumor pathogenesis of meningiomas and the future directions of meningioma treatments. Neurosurg Focus 30: E6, 2011.

12. Lamszus K, Kluwe L, Matschke J, Meissner H, Laas R and Westphal M: Allelic losses at 1p, 9q, 10q, 14q, and 22q in the progression of aggressive meningiomas and undifferentiated meningeal sarcomas. Cancer Genet Cytogenet 110: 103-110, 1999. 
13. Clark VE, Ersonomay EZ, Serin A, Yin J, Cotney J, Ozduman K, Avşar T, Li J, Murray PB, Henegariu O, et al: Genomic analysis of non-NF2 meningiomas reveals mutations in TRAF7, KLF4, AKT1, and SMO. Science 339: 1077-1080, 2013.

14. Chang X, Shi L, Gao F, Russin J, Zeng L, He S, Chen TC, Giannotta SL, Weisenberger DJ, Zada G, et al: Genomic and transcriptome analysis revealing an oncogenic functional module in meningiomas. Neurosurg Focus 35: E3, 2013.

15. Serna E, Morales JM, Mata M, Gonzalez-Darder J, San Miguel T, Gil-Benso R, Lopez-Gines C, Cerda-Nicolas M and Monleon D. Gene expression profiles of metabolic aggressiveness and tumor recurrence in benign meningioma. PLoS One 8: e67291, 2013.

16. Surace EI, Lusis E, Murakami Y, Scheithauer BW, Perry A and Gutmann DH: Loss of tumor suppressor in lung cancer-1 (TSLC1) expression in meningioma correlates with increased malignancy grade and reduced patient survival. J Neuropathol Exp Neurol 63: 1015-1027, 2004.

17. Schmidt M, Mock A, Jungk C, Sahm F, Ull AT, Warta R, Lamszus K, Gousias K, Ketter R, Roesch S, et al: Transcriptomic analysis of aggressive meningiomas identifies PTTG1 and LEPR as prognostic biomarkers independent of WHO grade. Oncotarget 7: 14551-14568, 2016.

18. Francesca M, Orzan FN, Eoli M, Farinotti M, Maderna E, Pisati F, Bianchessi D, Valletta L, Lodrini S, Galli G, et al: DNA microarray analysis identifies CKS2 and LEPR as potential markers of meningioma recurrence. Oncologist 16: 1440-1450, 2011.

19. Barrett T, Wilhite SE, Ledoux P, Evangelista C, Kim IF, Tomashevsky M, Marshall KA, Phillippy KH, Sherman PM, Holko M, et al: NCBI GEO: Archive for functional genomics data sets-update. Nucleic Acids Res 41 (Database Issue): D991-D995, 2013.

20. Tabernero MD, Maillo A, Gilbellosta CJ, Castrillo A, Sousa P, Merino M and Orfao A: Gene expression profiles of meningiomas are associated with tumor cytogenetics and patient outcome. Brain Pathol 19: 409-420, 2009.

21. Gautier L, Cope L, Bolstad BM and Irizarry RA: affy-analysis of Affymetrix GeneChip data at the probe level. Bioinformatics 20: 307-315, 2004.

22. Smyth GK: Limma: Linear models for microarray data. In: Bioinformatics and Computational Biology Solutions Using R and Bioconductor. Statistics for Biology and Health. Gentleman R, Carey V, Huber W, Irizarry RA and Dudoit S (eds): Springer, New York, NY, pp397-420, 2005.

23. Gene Ontology Consortium: The gene ontology project in 2008 . Nucleic Acids Res 36 (Database Issue): D440-D444, 2008.

24. Ogata H, Goto S, Sato K, Fujibuchi W, Bono H and Kanehisa M: KEGG: Kyoto encyclopedia of genes and genomes. Nucleic Acids Res 27: 29-34, 1999

25. Huang da W, Sherman BT and Lempicki RA: Systematic and integrative analysis of large gene lists using DAVID bioinformatics resources. Nature Protocol 4: 44-57, 2009.

26. Franceschini A, Szklarczyk D, Frankild S, Kuhn M, Simonovic M, Roth A, Lin J, Minguez P, Bork P, von Mering C and Jensen LJ: STRING v9.1: Protein-protein interaction networks, with increased coverage and integration. Nucleic Acids Res 41 (Database Issue): D808-D815, 2013.

27. Smoot ME, Ono K, Ruscheinski J, Wang PL and Ideker T: Cytoscape 2.8: New features for data integration and network visualization. Bioinformatics 27: 431-432, 2011.

28. Rooprai HK, Martin AJ, King A, Appadu UD, Jones H, Selway RP, Gullan RW and Pilkington GJ: Comparative gene expression profiling of ADAMs, MMPs, TIMPs, EMMPRIN, EGF-R and VEGFA in low grade meningioma. Int J Oncol 49: 2309-2318, 2016

29. Kirches E, Grunewald J, Von-Bossanyi P, Szibor R, Plate I, Krüger S, Warich-Kirches M and Dietzmann K: Expression of matrix metalloproteinases in a series of 12 meningiomas. Clin Neuropathol 20: 26-30, 2001

30. Roy R, Zhang B and Moses MA: Making the cut: Proteasemediated regulation of angiogenesis. Exp Cell Res 312: 608-622, 2006.

31. Bourboulia D and Stetler-Stevenson WG: Matrix metalloproteinases (MMPs) and tissue inhibitors of metalloproteinases (TIMPs): Positive and negative regulators in tumor cell adhesion. Semin Cancer Biol 20: 161-168, 2010.

32. Keller A, Ludwig N, Backes C, Romeike BF, Comtesse N, Henn W, Steudel WI, Mawrin C, Lenhof HP and Meese E: Genome wide expression profiling identifies specific deregulated pathways in meningioma. Int J Cancer 124: 346-351, 2009.
33. Fresno Vara JA, Casado E, de Castro J, Cejas P, Belda-Iniesta C and González-Barón M: PI3K/Akt signalling pathway and cancer. Cancer Treat Rev 30: 193-204, 2004.

34. Ma YY, Wei SJ, Lin YC, Lung JC, Chang TC, Whang-Peng J, Liu JM, Yang DM, Yang WK and Shen CY: PIK3CA as an oncogene in cervical cancer. Oncogene 19: 2739-2744, 2000.

35. Shayesteh L, Lu Y, Kuo WL, Baldocchi R, Godfrey T, Collins C, Pinkel D, Powell B, Mills GB and Gray JW: PIK3CA is implicated as an oncogene in ovarian cancer. Nat Genet 21: 99-102, 1999.

36. Chen F: JUN (V-Jun sarcoma virus 17 oncogene homolog (avian)). Atlas Genet Cytogenet Oncol Haematol 7: 85-86, 2003.

37. Wei C, Xiao W, Zhang K, Yin X, Lai J, Liang L and Chen D: Activation of c-Jun predicts a poor response to sorafenib in hepatocellular carcinoma: Preliminary clinical evidence. Sci Rep 6 : 22976, 2016

38. Blau L, Knirsh R, Ben-Dror I, Oren S, Kuphal S, Hau P, Proescholdt M, Bosserhoff AK and Vardimon L: Aberrant expression of c-Jun in glioblastoma by internal ribosome entry site (IRES)-mediated translational activation. Proc Natl Acad Sci USA 109: E2875-E2884, 2012.

39. Ameyar M, Wisniewska M and Weitzman JB: A role for AP-1 in apoptosis: The case for and against. Biochimie 85: 747-752, 2003.

40. Shaulian E and Karin M: AP-1 in cell proliferation and survival. Oncogene 20: 2390-2400, 2001.

41. Huhe M, Liu S, Zhang Y, Zhang Z and Chen Z: Expression levels of transcription factors c-Fos and c-Jun and transmembrane protein HAb18G/CD147 in urothelial carcinoma of the bladder. Mol Med Rep 15: 2991-3000, 2017.

42. Mahner S, Baasch C, Schwarz J, Hein S, Wölber L, Jänicke F and Milde-Langosch K: C-Fos expression is a molecular predictor of progression and survival in epithelial ovarian carcinoma. Brit J Cancer 99: 1269-1275, 2008

43. Winnay JN, Solheim MH, Dirice E, Sakaguchi M, Noh HL, Kang HJ, Takahashi H, Chudasama KK, Kim JK, Molven A, et al: PI3-kinase mutation linked to insulin and growth factor resistance in vivo. J Clin Invest 126: 1401-1412, 2016.

44. Thauvin-Robinet C, Auclair M, Duplomb L, Caron-Debarle M, Avila M, St-Onge J, Le Merrer M, Le Luyer B, Héron D, Mathieu-Dramard M, et al: PIK3R1 mutations cause syndromic insulin resistance with lipoatrophy. Am J Hum Genet 93: 141-149, 2013.

45. McCurdy CE, Schenk S, Holliday MJ, Philp A, Houck JA, Patsouris D, MacLean PS, Majka SM, Klemm DJ and Friedman JE: Attenuated Pik3rl expression prevents insulin resistance and adipose tissue macrophage accumulation in diet-induced obese mice. Diabetes 61: 2495-2505, 2012.

46. Seliger C, Meier CR, Becker C, Jick SS, Proescholdt M, Bogdahn U, Hau P and Leitzmann MF: Metabolic syndrome in relation to risk of meningioma. Oncotarget 8: 2284-2292, 2017.

47. Williamson CR, Khurana S, Nguyen P, Byrne CJ and Tai TC: Comparative analysis of renin-angiotensin system (RAS)-related gene expression between hypertensive and normotensive rats. Med Sci Monit Basic Res 23: 20-24, 2017.

48. Campisi J, Gray HE, Pardee AB, Dean M and Sonenshein GE: Cell-cycle control of c-myc but not c-ras expression is lost following chemical transformation. Cell 36: 241-247, 1984.

49. Fei X, Yuan Y, Xie L, Ran P, Xiang X, Huang Q, Qi G, Guo X, Xiao $\mathrm{C}$ and Zheng S: miRNA-320a inhibits tumor proliferation and invasion by targeting c-Myc in human hepatocellular carcinoma. Onco Targets Ther 10: 885-894, 2017.

50. Staal JA, Pei Y and Rood BR: A proteogenomic approach to understanding MYC function in metastatic medulloblastoma tumors. Int J Mol Sci 17: pii: E1744, 2016.

51. Finver SN, Nishikura K, Finger LR, Haluska FG, Finan J, Nowell PC and Croce CM: Sequence analysis of the MYC oncogene involved in the $\mathrm{t}(8 ; 14)(\mathrm{q} 24 ; \mathrm{q} 11)$ chromosome translocation in a human leukemia T-cell line indicates that putative regulatory regions are not altered. Proc Natl Acad Sci USA 85: 3052-3056, 1988.

This work is licensed under a Creative Common Attribution-NonCommercial-NoDerivatives 4.0 International (CC BY-NC-ND 4.0) License. 